\title{
O reconhecimento da língua para a compreensão do mundo: a questão da leitura
}

\author{
Claudia Toldo ${ }^{1}$ \\ Programa de Pós-Graduação em Letras, Universidade de Passo Fundo, Passo Fundo, RS, Brasil
}

Resumo: Este texto tem como objetivo fazer uma reflexão acerca dos sentidos do termo "frase" empregado no texto de Émile Benveniste Os níveis de análise linguística, produzido em 1962, relacionando-o com o texto $A$ forma e o sentido na linguagem, 1966. A questão posta é trazer as considerações presentes nesses textos de Benveniste, a fim de pensar o ensino da leitura na escola, enquanto uma atividade enunciativa. Insistimos, pois, em um ensino de uma língua que sirva para viver, o que requer do professor um trabalho cuja metodologia não se abrevie puramente em saberes metalinguísticos, pautados em nomenclaturas e classificações, mas que exija um domínio de exercício de linguagem - sempre singular a cada ato de apropriação das formas. Assim, investir em uma proposta de ensino da língua a partir de uma concepção enunciativa é oportunizar ao estudante sua posição de sujeito do seu discurso, do mundo, da sua história.

Palavras-chave: Enunciação; Forma e sentido na linguagem; Ensino de língua.

Title: Language recognition for understanding the world: the issue of reading

Abstract: This text aims to make a reflection on the meanings of the term "phrase" used in the text of Émile Benveniste The levels of linguistic analysis, produced in 1962, relating it to the text The form and meaning in language, 1966. The issue is to bring the considerations present in these texts of Benveniste in order to think the teaching of reading in school, as an enunciative activity. We insist, therefore, on a teaching of a language that is useful for living, which requires from the teacher a work whose methodology does not abbreviate purely in metalinguistic knowledge, based on nomenclatures and classifications, but that requires a domain of exercise of language - always unique in every act of appropriation of forms. Thus, investing in a language teaching proposal based on an enunciative conception is giving the student the opportunity to be the subject of his discourse, of the world, of his history.

Keywords: Enunciation; Form and meaning in language; Language teaching.

\footnotetext{
${ }^{1}$ Doutora em Letras pela Pontifícia Universidade Católica do Rio Grande do Sul, com Pós-doutorado em Linguística - Estudos do texto pela Universidade Federal do Rio Grande do Sul. Professora de Língua Portuguesa e Linguística do Curso de Letras da Universidade de Passo Fundo, RS. Professora e Coordenadora do PPGL Doutorado e Mestrado em Letras na mesma Universidade. Realiza pesquisas em Teorias da Enunciação, principalmente, estuda as reflexões teóricas de Émile Benveniste. Bolsista CNPq. Orcid: http://orcid.org/00000002-2960-0734. E-mail: claudiast@upf.br.
} 


\section{Palavras iniciais}

O objetivo deste texto é colocar em pauta a questão do sentido, a fim de entendê-lo para que atividades de leitura - tomadas aqui como atividades, necessariamente, enunciativas $^{2}$ - sejam realizadas em sala de aula da educação básica de forma producente. Este texto fará um percurso reflexivo, tomando, especialmente, os textos de Émile Benveniste Os níveis de análise linguística (PLG I, 1962) e A forma e o sentido na linguagem (PLG II, 1966), que serão aporte para o que pretendo apresentar a seguir. Esses textos, resultados de uma Conferência num Congresso de Linguística (1962) e de uma reflexão feita para filósofos (1966), trazem considerações sobre uma possível análise da língua e, também, as complexas relações entre forma e sentido. Recorto o que afirma Flores (2013, p. 128) quanto ao texto de 1962: "uma abordagem que privilegia as operações inter-relacionais das palavras no enunciado para expressar um sentido em uma dada situação enunciativa". É desse um sentido que quero tratar, junto com questões que envolvem pesquisas sobre a leitura na escola, principalmente na dimensão da recepção do texto, que - por mostrar ou não - faz pensar e, se possível, faz construir sentido(s). A partir das reflexões apresentadas por Benveniste em Os Níveis de Análise linguística, recorto os dois sentidos para o sentido de frase, deslocando-os para o que acredito necessário para um trabalho de texto, que prioriza sua leitura, sua compreensão, seus sentidos numa dimensão maior que o próprio texto, mas enunciativa.

Esta reflexão está organizada em três partes, a saber: na primeira, faço uma leitura parafrástica, mas já interpretativa, dos textos de 1962 e de 1966, destacando as principais considerações acerca dos níveis da análise linguística, ressaltando, ao final, os dois sentidos do conceito de frase, a fim de discuti-los e usá-los no recorte da parte seguinte; na segunda, faço uma discussão sobre o que entendo como leitura - em seu nível de recepção - na escola, aproximando disso os conceitos de sentido de frase; termino com uma reflexão que busca pensar o que se entende por leitura e o que significa realizar atividades de leitura em situação de sala de aula. É a formação do professor de língua que atravessa essa reflexão - condição essa primordial para o trabalho com e de língua na escola.

Aos apontamentos. Aos recortes teóricos. Aos deslocamentos. A uma possibilidade de pensar o ensino do texto e da leitura na escola.

\section{A análise linguística: a questão do sentido}

Esta seção está dividida em duas partes: na primeira, referencio o texto Os Níveis de análise linguística em que trato dos conceitos ali cunhados, discutidos e elaborados por Benveniste, principalmente acerca dos sentidos da palavra frase; a segunda diz respeito ao texto $A$ forma e o sentido na linguagem, a fim de estudá-lo e trazer essas noções gêmeas, discutidas num Congresso para filósofos, para analisar suas funções no domínio da linguagem ordinária. E para dar o tom da discussão, reproduzo as palavras de Benveniste (1966/2006, p. 223): "bem antes de servir para comunicar, a linguagem serve para viver", destacando o que

\footnotetext{
2 Texto que compõe pesquisa maior - CNPq.
} 
é Ihe próprio da linguagem: significar. Às partes que juntas elaboram o meu recorte neste momento.

Os níveis de análise: o início

Nesta seção, faço uma leitura do artigo Os níveis de análise linguística (PLG I, 1962), apontando para questões que são de meu interesse nesta reflexão. Benveniste, já de início, afirma que "a linguagem devia ser descrita como uma estrutura formal" (BENVENISTE, 1962/2005, p. 127), destacando que a realidade de um objeto não pode estar separada do método que o define. Para isso, propõe a noção de nível como procedimento da análise linguística, tendo presente a natureza articulada da linguagem e seu caráter discreto, considerando seus elementos/unidades constitutivas. Destaco que esses elementos constitutivos evidenciam uma arquitetura singular das partes de um todo - que aqui eu acredito poder assumi-lo como o texto que se lê em sala de aula. Benveniste (1962/2005, p. 127) também aponta o lugar em que se coloca: "o da língua como sistema orgânico de signos linguísticos". Eis o meu lugar também: o da língua; o terreno da língua, como diria Saussure. Para tanto, Benveniste evidencia que necessitamos delimitar os elementos através das relações que os unem. Ele traz duas operações para tratar da questão: a da segmentação e da substituição. A partir dessas operações, pergunto: o que isso significa e que importância tem para o que proponho aqui? O que isso interessa para pensar o sentido do texto no ato de leitura? Aqui inicio, propriamente dita, a reflexão que proponho.

Em relação ao primeiro questionamento, segmentar o texto significa segmentá-lo em porções cada vez menores, até se chegar em elementos que não podem ser reduzidos a unidades menores. Esses elementos são identificáveis por um procedimento: a substituição que eles admitem, tendo presentes as relações entre eles e entre os níveis em que se realizam. Não vou me deter aqui no detalhamento trazido por Benveniste a essa operação de substituição, mas destaco, por interesse particular, a afirmação de Benveniste (1962/2005, p. 128) sobre o método da distribuição:

consiste em definir cada elemento pelo conjunto do meio em que se apresenta, e por intermediário de uma relação dupla, relação do elemento com os outros elementos simultaneamente presentes na mesma porção do enunciado (relação sintagmática); relação do elemento com os outros elementos mutuamente substituíveis (relação paradigmática).

O importante dessa consideração é destacar as relações (assumo como necessárias) entre os elementos e entre os níveis (inferior e superior) que se organizam. Flores (2013, p. 131) destaca o posicionamento de Benveniste: "É por isso que o sentido é a condição linguística fundamental da análise de Benveniste: não se pode descer mais sem se perder o sentido". Ou seja, o importante é garantir que, em todas essas operações, as relações de sentido sejam garantidas. Isso demonstra que o que autoriza a segmentação e a distribuição de elementos entre si e entre níveis é o sentido, pelo fato de revelar sua condição linguística. Mais uma vez, ocupo-me das palavras de Benveniste (1962/2005, p. 130) para explicar: "O 
sentido é de fato a condição fundamental que todas as unidades de todos os níveis devem preencher para obter o status linguístico". E acrescenta (BENVENISTE, 1962/2005, p. 130): “A língua não poderia funcionar de outra maneira". Não se pode esquecer de que nos colocamos no lugar da língua e, assim, exige-se que o sentido seja tomado como condição indispensável da análise linguística.

Como já disse, não vou me deter no detalhamento da segmentação apresentada por Benveniste nesse texto, mas tomar as relações de sentido entre os constituintes (fonemas, signos/palavras, frase). Essas relações entre esses elementos constituem um todo. E isso só se realiza pelo sentido que autoriza determinadas relações. Essas relações são locais, ou seja, estão numa relação sintagmática em que se definem pela relação que as unidades estabelecem entre si. São relações que devem oportunizar o reconhecimento de seus elementos/constituintes/unidades, para que sejam compreendidos nesse universo menor, o do nível específico. Esses constituintes podem operar em níveis mais altos à medida que se habilitam a integrá-los. Benveniste traz o nível da frase como o mais alto e como um todo, que é repartido entre o conjunto dos seus constituintes. Evidencia o termo "palavra" como um elemento constituinte da frase que estabelece relações sintagmáticas, que constituem os enunciados, as frases (tomados aqui como sinônimo). Assim, pode-se perceber em Benveniste que o limite superior da análise é a frase, que se define por seus elementos relacionados sintagmaticamente. Com isso, duas relações se apresentam: as relações distribucionais e as relações integrativas. Benveniste ocupa-se em especial da segunda. Por quê? Porque o que interessa é a transição de um nível a outro que se dá pela possibilidade de constituir sentidos dos elementos independentemente do nível que se colocam. Nas palavras de Benveniste (1962/2005, p. 133, grifo meu):

\footnotetext{
Um signo é materialmente função dos seus elementos constitutivos, mas o único meio de definir esses elementos como constitutivos consiste em identifica-los no interior de uma unidade determinada onde preenchem uma função integrativa. Uma unidade será reconhecida como distintiva num determinado nível se puder identificar-se como 'parte integrante' da unidade de nível superior, da qual se torna integrante.
}

Ou seja, um elemento é constitutivo se possui o status linguístico de poder integrar um nível superior. O constituinte deverá ser reconhecido como tal para ser parte integrante da unidade superior. Isso é significativo, pois no ato de ler - ao menos numa primeira leitura - os elementos precisam ser reconhecidos para estabelecerem relações (outras) de sentidos com outros elementos e, assim, estabelecer as relações que constituem o todo - que considero aqui o texto. Volto a isso mais tarde.

A partir dessas considerações, Benveniste (1962/2005, p. 134) questiona: “Qual é, no sistema dos signos da língua, o alcance dessa distinção entre constituinte e integrante?", e responde: "Funciona entre dois limites". Que limite? O superior e o inferior da análise; nesse limite, os elementos se constituem e se reconhecem como tal e, por isso, podem integrar um nível superior. Nesse limite, ainda se tem o que pode determinar a distinção de constituinte e integrante. Benveniste afirma (1962/2005, p. 134): “É uma função de importância 
fundamental. Encontra-se nisso o princípio racional que governa, nas unidades dos diferentes níveis, a relação entre FORMA e SENTIDO". Assim, Benveniste (1962/2005, p. 135) associa essas noções ao par forma e sentido, afirmando:

Forma e sentido devem definir-se um pelo outro e devem articular-se juntos em toda extensão da língua. As suas relações parecem-nos implicadas na própria estrutura dos níveis e na das funções que a elas correspondem, que aqui designamos constituinte e integrante.

Benveniste (1962/2005, p. 135-136) explica ainda que, quando se reduz uma unidade a seus constituintes, reduz-se aos seus elementos formais (relações sintagmáticas resultado do arranjo da sintaxe da língua). Afirma o linguista: "a forma de uma unidade linguística define-se como a sua capacidade de dissociar-se em constituintes de nível inferior. O sentido de uma unidade linguística define-se como a sua capacidade de integrar uma unidade de nível superior". Sublinho, portanto, que forma e sentido são propriedades que não podem ser vistas separadas, suas relações são mútuas, uma vez que arquitetam as relações possíveis em diferentes níveis. Essa interdependência entre as gêmeas noções - forma e sentido - são de peculiar interesse nesta reflexão, uma vez que acredito que é nessa relação e nessa união que o sentido inicia seu percurso constitutivo. E aqui, Benveniste (1962/2005, p. 136) problematiza, cujo problema coaduno: "A noção de sentido, porém, tem outro aspecto". Esse problema, do outro aspecto, me interessa. Evoco as palavras de Flores (2013, p. 134) na seguinte síntese:

Benveniste enfatiza dois pontos aqui: Quando se diz que um elemento tem sentido, afirma-se que ele tem a propriedade de constituir e integrar; Quando se pergunta qual é o sentido, afirma-se que a língua serve para estabelecer uma certa relação com o mundo e, nesse caso, impõe-se outra tarefa de descrição e caracterização, bastante distinta da anterior, pois está-se agora no plano do discurso.

Com esse problema referido por Benveniste, identificam-se - na verdade - dois sentidos para o conceito de frase. O primeiro diz respeito a um sentido de natureza formal, trazido pela distinção feita entre as relações distribucionais (com suas unidades constituintes) e as integrativas (com suas unidades integrantes); o segundo sentido de frase liga-se à pergunta que Benveniste faz: "Qual é o sentido" que releva uma ideia de frase que pertence ao discurso. O outro aspecto de que já pontuei antes. Assim, com a frase "se deixa o domínio da língua como sistema de signos e se entra num outro universo, o da língua como instrumento 3 de comunicação cuja expressão é o discurso" (BENVENISTE, 1962/2005, p. 139). Há aqui duas realidades diferentes que se (entre)cruzam. Diz Benveniste (1962/2005, p. 139): "Há de um lado a língua, conjunto de signos formais, destacados pelos procedimentos rigorosos, escalonados por classes, combinados em estruturas e sistemas; de outro, a manifestação da língua na comunicação viva".

\footnotetext{
${ }^{3}$ Não vou trazer aqui a discussão feita por Benveniste no texto Da subjetividade na linguagem sobre a língua enquanto instrumento de comunicação.
} 
E insiste: "A frase pertence bem ao discurso. E por aí mesmo que se pode defini-la: a frase é uma unidade do discurso" (BENVENISTE, 1962/2005, p. 139). Desse modo, identificase que Benveniste define nível em função das relações distribucionais e integrativas que cada uma de suas unidades traz consigo. Flores (2013, p. 136) sintetiza, apontando a relevância disso tudo. Traz duas ponderações com as quais me solidarizo:

A primeira e mais evidente é que há sempre relações de fronteira entre os planos da língua. Um elemento se define, no mínimo, pelas relações distribucionais e integrativas. A segunda, menos óbvia, é a que se pode inferir de uma afirmação que aparece no fim do artigo: 'É no discurso atualizado em frases que a língua se forma e se configura. Aí começa a linguagem' (PLG I:140). Ou seja, nada em matéria de linguagem pode ser estudado se não se levar em conta o discurso (a enunciação?).

Sim. A enunciação. É ela que vai me orientar a fazer o recorte que aqui proponho: os dois sentidos para o sentido de frase - o formal e enunciativo - permitem, na minha perspectiva, trazer à discussão o conceito de leitura. Desse modo, questiono: quando se lê um texto, que movimento com a língua o leitor realiza? Que movimento o professor precisa oportunizar aos seus alunos, para que o sentido, resultado das relações entre os constituintes do nível, seja construído? Como chegar a "ao qual sentido", objetivo último do trabalho do texto?

Antes de ir adiante, convoco dois conceitos, já anunciados por Benveniste em Os Níveis de Análise Linguística, para detalhá-los melhor e dar-lhes um lugar nesta reflexão que proponho. A saber: forma e sentido, trabalhados no texto de 1966 A forma e o sentido na linguagem.

\section{A forma e o sentido na linguagem e o funcionamento da língua}

Esta seção destina-se, então, ao estudo do texto de 1966, elaborado e proferido como conferência inaugural de um Congresso de Filósofos. Nesse texto, Benveniste parte de um distanciamento do que se tomavam os conceitos forma e sentido, tidos como duas faces em oposição. Para ele, essas noções não se opõem, mas trazem um problema central: o da significação. E é partir disso que ele elabora a reflexão (difícil) da dupla a forma e o sentido na linguagem que intitulam sua reflexão.

Diante dessa constatação, Benveniste (1966/2006 p. 222) já se coloca: “bem antes de servir para comunicar, a linguagem serve para viver". Isso porque sem ela [a linguagem] não há homem, não há sociedade, não há língua, não há enunciação. E a partir disso, inicio o recorte que proponho para este momento.

À maneira de Saussure, Benveniste traz as relações entre forma e sentido, no domínio linguístico, partindo da noção de língua, vista como um sistema de signos, e associa a isso um estudo que para ele é fundamental e necessário - o estudo da significação.

Isso traz a discussão que o signo é uma unidade semiótica. Eis o primeiro domínio - o domínio semiótico, tratado neste texto A forma e o Sentido na linguagem. Detalho esse domínio, sob um recorte particular, propósito deste texto. Benveniste reconhece que 
Saussure não traz essa relação entre forma e sentido, mas pontua como algo necessário para explorar essas noções gêmeas. Benveniste aponta que uma unidade semiótica contém uma dupla relação: a noção de signo enquanto unidade e a noção de signo dependente da ordem semiótica. Aqui Benveniste define o signo enquanto unidade, que trata como particular da língua e que não se divide, mas se decompõe. Desse modo, aponta para o texto Os níveis de análise Linguística (1962) em que trata do limite dessa (de)composição, destacando sua peculiaridade: a significação. Nas palavras de Benveniste (1966/2006, p. 225)

É por isso que ela não se deixa dividir, mas decompor; suas unidades são elementos de base em número limitado, cada um diferente do outro, e suas unidades se agrupam para formar novas unidades, e estas por sua vez poderão formar outras ainda, de um nível cada vez superior. Ora, a unidade particular que é o signo tem por critério um limite inferior: este limite é o da significação; não podemos descer abaixo do signo sem perder a significação.

Eis aí a noção que aproxima a reflexão feita nos textos de 1962 - Os Níveis de Análise Linguística e o de 1966 - A forma e o sentido na linguagem: a da significação. Assumo esse conceito como algo que faz a especificidade da língua como sistema, como o que estrutura a língua, revelando-se nas e pelas formas dessa língua. Apoio-me nas palavras de Normand (2009, p. 176), quando discute o problema da significação em Benveniste. Ela diz:

Benveniste, como vimos, descreve as formas e as interpreta sem se colocar a questão de saber se é legítimo proceder assim. Como todos os comparatistas, ele parte da evidência de que as formas linguísticas significam; simplesmente ele não se contenta em descrevê-las enquanto formas, mas afirma que é preciso se interessar por sua função significante e relacionar particularidades formais e particularidades semânticas, depreendendo, assim, o que chama de as estruturas de uma língua.

Essa inconformidade na descrição das formas - como procedimento de leitura - que me inquieta. Benveniste considerava que a linguagem tem como função dizer alguma coisa. Mas o que é exatamente isso? Como chegar a esse "alguma coisa"? Vejo que esse é o sentido, colocado na pergunta: qual é o sentido? Esse é o problema da significação que nos orienta a pensar a leitura na escola. Essa significação, quando vista no signo, precisa levar em conta que o signo é uma unidade semiótica da língua, dotado de significação na comunidade dos que usam a língua. Não podemos esquecer que a totalidade do signo traz a totalidade da língua. Esse signo apresenta duas faces: o significante (SE) e o significado (SO). O SE condiciona e determina o SO - aspecto formal da entidade signo; o SO traz outra questão, que pode ser expressa pela seguinte questão: "Isto significa ou não?". Destacamos que significar, nesse caso, é o signo ter sentido para os que manuseiam a língua. Ou seja, usam a língua para viver.

Assim, Benveniste elege dois critérios para avaliar se um signo existe ou não, a saber: o uso; a compreensão da língua. Nas palavras de Benveniste (1966/2006, p. 227): “É no uso da língua que um signo tem existência; o que não é usado não é signo; ou está na língua, ou está fora da língua". Portanto, nesse domínio semiótico, encontramos o signo que deve ser identificado no interior da língua, considerando seu SE como o aspecto formal do signo, e o SO como o que possibilita a existência do signo porque significa. Assim, percebemos que nessa 
dimensão o signo precisa ser identificado e reconhecido, para - a partir de então - construir sentido no discurso. Isso nos diz que estamos diante da dupla função da língua: a de reconhecer a forma como um signo e a de compreender o novo valor desse signo em uso. Por que não dizer, nos diferentes textos em que é empregado e precisa ser lido.

Em suma, no domínio semiótico, temos um signo que se distingue de outros signos. Isso se dá no sintagma. Já me arrisco a adiantar: aqui temos aquele primeiro nível de leitura o do arranjo sintático da língua no sintagma. Apoio-me em Benveniste (1966/2006, p. 227) que diz: "Cada signo entra numa rede de relações e de oposições com os outros signos que o definem, que o delimitam no interior da língua". Isso deixa claro que se colocar no domínio do semiótico é colocar-se no domínio intralinguístico.

Diante disso tudo, poderíamos, plagiando Benveniste, lembrar o que tratamos na seção anterior e perguntar: "E a frase? Qual sua função comunicativa na língua?" (BENVENISTE, 1966/2006, p. 228). Como já considerei, a frase traz a possibilidade de responder a uma outra questão: "Qual é o sentido?". Acredito que fica claro que entro em outro momento. Trago as reflexões de Benveniste acerca de um outro domínio; uma outra forma de ser língua: o domínio semântico. Aqui temos a língua em ação. A língua em uso. A língua toda. Benveniste (1966/2006, p. 229) afirma:

vemos desta vez na língua sua função mediadora entre o homem e o homem, entre o homem e o mundo, entre o espírito e as coisas, transmitindo informação, comunicando a experiência, impondo a adesão, suscitando a resposta, implorando, constrangendo; em resumo, organizando toda a vida dos homens. É a língua como instrumento da descrição e do raciocínio.

Essa afirmação de Benveniste evidencia que a "expressão semântica por excelência é a frase". Saímos assim do universo do significado do signo e entramos no universo do que o locutor quer dizer, da atualização da língua. Os domínios (semiótico e semântico) se diferem: o semiótico evidencia uma propriedade (interna) da língua que deve ser reconhecida; o semântico resulta da atividade do locutor que usa a língua. Benveniste (1966/2006, p. 230) explica: "O signo semiótico existe em si, funda a realidade da língua, mas ele não encontra aplicações particulares; a frase, expressão do semântico, não é senão particular". Diante disso, concluo que o signo estabelece relações internas na língua; a frase liga-se ao externo da língua. O signo tem o SO como inerente; o sentido da frase implica a relação com o mundo, com a situação do discurso, evidencia a atitude do locutor. Aponto aqui, para um segundo nível de leitura, o que se refere ao segundo sentido de frase: ler a frase enquanto elemento pertencente ao discurso. Assim, temos outras duas noções de forma e sentido, que realmente não se opõem, mas se relacionam e se amalgamam à medida que trazem problemas como o da significação.

Quero resumir uma questão aqui: os dois sentidos de frase trazem dois movimentos de leitura; as duas formas de ser língua trazem os mesmos dois movimentos de leitura. Ou seja, um desfecho dessa reflexão me parece possível fazer: 1) ler significa ler o signo e compreendê-lo num nível intrínseco da língua; 2) ler significa, ainda, responder à pergunta "qual é o sentido". Considerando este fechamento, proponho considerar que os domínios 
semiótico e semântico estão no centro da reflexão do ensino da leitura. Mais uma vez, tomo Benveniste como apoio a esta minha conclusão:

Assim, o "sentido" da frase está na totalidade da ideia percebida por uma compreensão global: a "forma" se obtém pela dissociação analítica do enunciado processada até as unidades semânticas, as palavras. Além disso, as unidades não podem mais ser dissociadas sem deixar de preencher sua função. Esta é a articulação semântica.

Como resume Flores (2013, p. 144), "o sentido da frase depende de uma compreensão global; a forma depende de uma dissociação analítica". Eis o trabalho de leitura producente que proponho a ser feito na escola. Ensinar a ler, significa ensinar a perceber os dois sentidos de frase trazidos até aqui.

Passemos à próxima parte.

\section{Leitura do texto: atividade que mobiliza sentidos}

Nesta seção, dedico-me a pontuar algumas observações acerca de texto e da leitura desse texto. Chamo a atenção para o fato de que observar os modos de ler mostra que, ao utilizar o texto, os sujeitos realizam uma atividade constante de relacionar-se (consigo mesmo, com os outros, com o mundo) e, assim, a leitura faz sentido. Como chegar a ele, ao sentido? É isso que me proponho a pensar.

Algumas observações inicias, parece-me, são necessárias, a saber: registro de imediato que mesmo que Benveniste não reflita sobre as noções de leitura e de texto ao longo de seus Problemas de linguística geral, acredito que é possível inferir de seus trabalhos e reflexões sobre o funcionamento da língua, uma noção do conceito de texto. Com isso, quero dizer que o fato de o autor não identificar essas noções explicitamente, não implica a inexistência da noção, mesmo que sob outra designação.

A título de exemplo do que estou trazendo, observemos o que diz o Dicionário de linguística da enunciação (FLORES et al., 2009) acerca do termo "enunciado", que vejo abrigar o conceito de texto, em Benveniste:

manifestação da enunciação, produzida cada vez que se fala. Na medida em que a enunciação é processo, o enunciado pode ser considerado o produto da enunciação e inclui pessoa, tempo e espaço. O enunciado tem existência em um determinado momento em que a língua é mobilizada por um locutor. (FLORES et al., 2009, p. 107).

Assim, considero que há aí uma indicação do que seja um texto. Com o texto Os Níveis de Análise Linguística, trabalhado na seção anterior, mobilizo a ideia que Benveniste traz sobre o nível da frase como o mais alto e como um todo, que é repartido entre o conjunto dos seus constituintes. Adoto, a partir de agora, essa noção de todo, como uma noção correlata a texto. Um todo que se organiza pela relação estabelecida entre seus elementos constitutivos e integrantes. Um todo que traz um sentido definido por suas relações internas. Um todo que atualiza a língua e possibilita a questão: Qual é o sentido desse todo; meu intuito é provocar 
a reflexão. Obviamente não tenho respostas e receitas para os problemas vividos numa sala de aula de educação básica, mas penso que posso propor uma reflexão sobre o ensino da língua portuguesa - enquanto língua materna, especialmente a leitura de textos - mais produtivo, tomando como ponto de partida e de chegada o texto e sua organização. Acredito que podemos tomá-lo em análise, considerando que, para Benveniste, o dizer de um sujeito - quando coloca a língua em funcionamento - torna-o homem na língua e, para esta reflexão, acrescentaria torna-o leitor.

Faço referência às ponderações de Teresa Colomer, na obra "Andar entre livros", de 2007, que afirma que, depois de quinze ou dezesseis anos, a maioria dos adolescentes deixa as aulas de escolaridade obrigatória e o faz sem uma característica de leitores. Isso mostra que, se os objetivos do ensino da leitura na escola tivessem sido cumpridos, "todos eles deveriam ser leitores competentes em uma sociedade alfabetizada" (COLOMER, 2007, p. 49). Afirma ainda:

\footnotetext{
Examinar os aspectos que se incluem nesses estudos permite uma primeira constatação explícita das expectativas sociais sobre o que se desejaria que os cidadãos soubessem fazer com relação à leitura. Analisar os resultados permite traçar um retrato representativo tanto da média escolar como da distância que a separa desses desejos. É algo que ajuda a estabelecer a tarefa que a escola tem pendente. (COLOMER, 2007, p. 49).
}

Isso nos mostra que algo não está acontecendo na escola com o ensino da leitura. A escola levou essas crianças e adolescentes a lerem, a conhecerem o texto, a aproximarem-se do mundo das letras pela leitura, mas não os ajudou a se tornar um - efetivo - leitor. Muitos veem a leitura como algo próprio da atividade escolar, e não algo como constitutivo de um sujeito que se propõe a tal, porque sabe - efetivamente - ler. Porque aprendeu a ler. Nessa perspectiva, entendo que aprender/saber a ler consiste em dominar a estrutura da língua, reconhecê-la, entender suas combinações e construir sentido(s) a partir da leitura que faz do emprego das formas da língua, em uso. $E$ isso o professor deve ensinar.

Assim pergunto: quantos de nossos professores da educação básica entenderam isso? Ou seja: quantos professores tomam a língua, colocam-na em funcionamento e tornam-se sujeitos de seu dizer porque sabem "manejá-la", "forjá-la" "ensiná-la"? Acredito que aprender língua portuguesa na escola significa aprender a usar a língua nas situações mais diversas em que a enunciação se impõe entre falantes de uma língua. Eis uma fragilidade: isso nem sempre acontece nas salas de aula da educação básica. Talvez porque a escola não ofereça condições; talvez porque os estudantes estejam "difíceis"; talvez porque estamos vivendo uma crise no que respeita a função da escola na sociedade atual; talvez porque falte o conhecimento de uma teoria linguística aos professores que possibilite uma abordagem outra do texto em suas aulas de língua materna. Ficarei com esta última.

Retomando a questão da leitura como um exercício de linguagem, chamo a atenção para a necessidade de entendimento dos que trabalham com a língua em situação de ensino, de ver a leitura como esse exercício. Afinal, as atividades de leitura têm uma razão de ser: contribuir para a formação da pessoa, enquanto sujeito que lê, reconhece a língua e constrói 
sentido. Isso está ligado à formação e à construção da sociabilidade, realizada através de atividades que confrontam textos de gerações anteriores e contemporâneos que abordam a atividade humana por meio da linguagem. Essa confrontação - pela linguagem - traz a diversidade social e cultural de uma sociedade, na qual encontramos o homem falando com outro homem, construindo a cultura, a sociedade, testemunhando a vida retratada e contada nos textos - em suas mais variadas manifestações de linguagem -, aproximando as pessoas, tornando-as sujeitos de seu próprio dizer, protagonistas de histórias reais que encantam e apavoram por sua genialidade. São essas histórias que movem uma sala de aula que toma o texto e faz da sua leitura uma possibilidade de exercício de linguagem; que faz dele, o texto, um mundo de possibilidades.

Para encerrar esta reflexão, proponho um questionamento: o que significa pensar o trabalho de leitura de texto em sala de aula a partir de uma concepção enunciativa de língua? Destaco ainda que discutir ensino de língua materna implica trazer presente o conceito (enunciativo) de língua. Na perspectiva de Émile Benveniste, a língua, enquanto sistema, expressa o que queremos dizer, transformando-se em linguagem. Benveniste afirma que a língua se organiza como uma grande estrutura, portadora de estruturas menores e de muitos níveis. Assim, as formas da língua, relacionadas em diferentes níveis, arquitetam o texto e apontam o que deve ser lido.

A partir disso, trago os apontamentos da primeira seção, discutidos a partir do texto de Émile Benveniste, 1962: a discussão dos níveis da análise da língua, excepcionalmente os sentidos do sentido do nível mais alto, o da frase. Assim, levanto dois tipos de leitura que me parecem necessários, tomando por base os dois sentidos do sentido de frase, de ser reclamados, uma vez que trazem duas realidades:

a) ler, num primeiro movimento, significa ler as formas da língua que organizam seus níveis, o todo;

b) ler, num segundo movimento, significa responder à pergunta: qual é o sentido do texto?

Isso significa que o trabalho com o texto na sala de aula requer um cuidado ao ler seus constituintes, construindo o sentido possível em suas relações, e um trabalho mais complexo ao responder qual o sentido daquele texto.

Ler, nesse primeiro movimento, significa fazer um trabalho de reconhecimento das formas da língua em suas combinações (intra)níveis, tomando a língua como um sistema de signos. E ler, num segundo movimento, significa tomar o todo realizado e atualizado pela frase, considerada neste estudo como uma criação sem limite; como a própria vida da linguagem em ação. A leitura de um texto deve ser provocada a partir desses dois movimentos: ler é reconhecer as formas da língua e suas relações, construindo seu sentido e, a partir disso, ler e compreender o sentido do todo que atualiza a língua em frases. O leitor do texto deve aprender a reconhecer e compreender o que o conduziu a projetar no texto o que não está lá, mas o que o perpassa, ou seja, construir tal sentido e não outro. Acredito que na sala de aula podem coexistir esses dois movimentos de leitura do texto em diferentes atividades. É a partir das leituras - desses dois movimentos - que sentidos podem ser 
compartilhados. O domínio desses movimentos põe em tensão o reconhecimento e a compreensão das formas da língua e seus sentidos possíveis que se estabelecem no vai e vem de relações entre os níveis da análise linguística. Isso traz um trabalho muito mais producente de fonética, morfologia, sintaxe - uma vez que o próprio Benveniste aponta que os níveis da análise não são como camadas que se somam, mas como relações amalgamadas que seus elementos constitutivos mantêm entre si.

Tomo mais uma vez as palavras de Flores (2013, p. 145) que, levando em consideração o que Benveniste (1966/2006, p. 229) afirma, "o signo e a frase são dois mundos distintos e que exigem descrições distintas", defende: "De um lado, a língua como semiótico; de outro, a língua como semântico". Isso deve ser considerado quando se ensina a ler na escola.

Então, ter presente essa última observação - os dois sentidos do sentido de frase oportuniza ver em que medida esses conceitos são cunhados por Benveniste. Para mim, isso traz à cena uma forma de reconhecimento da língua para a compreensão do mundo. Eis a atividade da leitura. A escrita deixaremos para depois, mas desde já a consideramos uma forma de ler e compreender o mundo por escrito. Essa é outra conversa.

\section{Palavras finais}

Nunca terminamos definitivamente. Mas é hora de dizer algo conclusivo.

Tomando essas reflexões sumárias que faço neste texto, considero, entre tantas possibilidades de pensar a leitura na escola, esta indispensável: ensinar língua e leitura é ensinar que podemos usar a mesma forma linguística, mas a cada vez a empregamos de um modo único e singular. $E$ isso deve ser identificado e reconhecido, a fim de construir o sentido do que se diz. Assim se ensina: lendo textos e analisando o emprego das formas, identificandoas e reconhecendo-as, mostrando que, a cada vez que o locutor toma a língua e se enuncia, produz sentidos que podem ser escritos em textos que dizem o que esse sujeito escolheu dizer. Textos que trazem o que sujeitos dizem, o que conseguiram ler dos textos que tomaram para compreender. Segundo Flores (2013b, p. 108), "apesar da identidade da forma (isto é, apesar de as formas serem iguais), há a singularidade de cada um." Ou seja, sujeito leitor nas nossas aulas de português que aprende a usar a língua e aprende a assumir-se como eu, que toma a língua e exercita a linguagem que Ihe é constitutiva, exercita sua experiência de dizer eu, de ser eu.

Portanto, as leituras propostas em sala de aula necessitam de atenção. Necessitam de cuidado. Necessitam de uma concepção de língua e de linguagem, por parte dos docentes, que deem conta de um trabalho linguístico que busque, sim, trabalhar as competências de desenvolver leitura. Porém, se o trabalho docente de leitura não priorizar um trabalho com as formas da língua e com os sentidos daí resultantes, nossos alunos, além de não construírem as competências desejadas, não vão garantir seus direitos de aprendizagens e, principalmente, não serão sujeitos de seu tempo e de seu dizer, com o outro, o professor talvez através do exercício da linguagem. Não serão sujeitos, pois não aprenderão a tomar a língua, em exercícios inteligentes de uso da língua, para ler o mundo, os textos que o 
completam e escrever sua própria história. Conforme Benveniste (1965/2006, p. 80), mais uma vez, "é sempre ao ato de fala no processo de troca que remete a experiência humana inscrita na linguagem." Portanto, precisamos realizar exercícios significativos de língua, pelo texto, para que essas relações se concretizem. Com certeza, isso não se dá com atividades de classificação gramatical, mas com exercícios em que o texto é a unidade de trabalho, o texto é a unidade em que se observa o emprego singular das formas da língua e o sentido que dali é possível construir, o texto deve ser tomado como possibilidade de leitura do mundo e de escrita desse mundo, sob o olhar dos nossos alunos, enquanto sujeitos da enunciação.

Acredito que um trabalho de texto em que se observa o emprego das formas da língua, partindo daí ao sentido e à verificação de como se constrói mundos possíveis pela língua, podemos fazer do trabalho com a língua portuguesa na escola uma oportunidade de construir saberes, experiências, leituras e escritas do/no mundo.

Insisto: isso se ensina. E se ensina na escola. Já disse isso.

\section{Referências}

BENVENISTE, Émile. (1958). Da subjetividade na linguagem. In: BENVENISTE, Émile. Problemas de linguística geral I. 5. ed. Tradução Maria da Glória Novak e Maria Luisa Salum. Campinas, SP: Pontes Editores, 2005. p. 284-293.

BENVENISTE, Émile. (1962). Os níveis da análise linguística. In: BENVENISTE, Émile. Problemas de linguística geral I. 5. ed. Tradução Maria da Glória Novak e Maria Luisa Salum. Campinas, SP: Pontes Editores, 2005. p. 127-140.

BENVENISTE, Émile. (1965). A linguagem e a experiência humana. In: BENVENISTE, Émile. Problemas de linguística geral II. 2. ed. Tradução Eduardo Guimarães et al. Campinas, SP: Pontes Editores, 2006. p. 68-80.

BENVENISTE, Émile. (1966-1967). A forma e o sentido na linguagem. In: BENVENISTE, Émile. Problemas de linguística geral II. 2. ed. Tradução Eduardo Guimarães et al. Campinas, SP: Pontes Editores, 2006. p. 220-242.

COLOMER, Teresa. Andar entre livros: a leitura literária na escola. São Paulo: Global, 2007.

FLORES, Valdir do Nascimento et al. (Org.). Dicionário de Linguística da Enunciação. São Paulo: Contexto, 2009.

FLORES, Valdir do Nascimento. Introdução à Teoria Enunciativa de Benveniste. São Paulo: Parábola, 2013.

NORMAND, Claudine. Convite à linguística. São Paulo: Contexto, 2009.

SAUSSURE, Ferdinand de. Curso de linguística geral. Tradução Antônio Chelini, José Paulo Paes, Izidoro Blikstein. Organização Charles Bally, Albert Sechehaye. Colaboração de Albert Riedlinger. 27. ed. São Paulo: Cultrix, 2006.

Recebido em: 10/12/2019. Aceito em: 09/03/2020. 